\title{
DESENVOLVIMENTO E PRODUTIVIDADE DA CULTURA DA BATATA IRRIGADA POR GOTEJAMENTO EM DOIS SISTEMAS DE CULTIVO ${ }^{1}$
}

\section{JOÃO A. SILVA ${ }^{2}$, REGINA C. M. PIRES ${ }^{3}$, EMILIO SAKAI ${ }^{3}$, TONNY J. A. SILVA ${ }^{4}$, JOSÉ E. ANDRADE ${ }^{5}$, FLÁVIO B. ARRUDA ${ }^{3}$, RINALDO O. CALHEIROS ${ }^{3}$}

\begin{abstract}
RESUMO: O presente trabalho avalia o desenvolvimento e a produtividade da cultura da batata cv. Monalisa, irrigada por gotejamento, conduzida em parcelas com o plantio tradicional em linhas simples (LS), espaçadas de 0,75 m, e em linhas duplas (LD), com espaçamentos alternados de 0,60 e 0,90 m, dispostos em blocos ao acaso, com oito repetições. O cultivo em LS recebeu uma linha de tubogotejador por linha de plantas, enquanto no cultivo em LD, o tubogotejador foi instalado entre as linhas de menor espaçamento. O plantio da batata foi realizado em 19 de abril de 2005, e a colheita, em 15 de agosto de 2005, em Itobi - SP, sendo a mesma densidade de plantio nos dois tratamentos. A matéria seca da parte aérea e o índice de área foliar não diferiram estatisticamente nos dois sistemas de cultivo. $\mathrm{O}$ sistema de plantio em LD proporcionou maior produtividade de batatas, comparado ao sistema em LS. A qualidade da produção foi semelhante em ambos os sistemas de cultivo.
\end{abstract}

PALAVRAS-CHAVE: irrigação, manejo da água, Solanum tuberosum L.

\section{POTATO CROP GROWTH AND YIELD TRICKLE IRRIGATED UNDER TWO CULTIVATION SYSTEMS}

\begin{abstract}
This work evaluates the vegetative growth and yield of irrigated potato plants cv. Monalisa under traditional planting in a single row (TP), spaced by $0.75 \mathrm{~m}$, and under a double row planting (DL), spaced by 0.60 and $0.90 \mathrm{~m}$ between rows, in a complete randomized block design with eight replications. The TP had one trickle line per row and the DL had one trickle line placed in the middle of the narrower row space. The planting date was in April 19, 2005 and the harvest was on August 15, 2005, in Itobi - SP, Brazil. Plant population was the same for both treatments. Leaf area index and above ground dry matter were not different in both planting system. The double row planting system provided a better final yield. Yield quality wasn't affected by the cultivation systems.
\end{abstract}

KEYWORDS: irrigation, water management, Solanum tuberosum L.

\section{INTRODUÇÃO}

A batata (Solanum tuberosum L.), originária de áreas tropicais de elevada altitude, é considerada a quarta fonte de alimento para a humanidade, perdendo apenas para o trigo, arroz e milho. No Estado de São Paulo, essa espécie vegetal é cultivada o ano inteiro, sob irrigação intensiva ou complementar às chuvas, alcançando produtividade média de $23,3 \mathrm{t} \mathrm{ha}^{-1}$, valor esse acima da média mundial e nacional, de $16,2 \mathrm{t} \mathrm{ha}^{-1}$ e $19,7 \mathrm{t} \mathrm{ha}^{-1}$, respectivamente (NEHMI et al., 2004).

A produtividade da cultura pode ser afetada pelas condições climáticas, edáficas e tratos culturais, bem como pelo potencial genético e pela sanidade da batata-semente. A disponibilidade

\footnotetext{
${ }^{1}$ Trabalho financiado com recursos do Edital CT-HIDRO/Finep/Netafim/Fundag.

${ }^{2}$ Engo Agrônomo, Centro de Pesquisa e Desenvolvimento de Ecofisiologia e Biofísica, Instituto Agronômico (IAC), Campinas - SP, Caixa Postal 28, Fone: (0XX19) 3241.5188, ramal 351, joao_agr@yahoo.com.br . Bolsista do CNPq.

${ }^{3}$ Eng ${ }^{o}$ Agrônomo, Pesquisador Científico, Centro de Pesquisa e Desenvolvimento de Ecofisiologia e Biofísica, Instituto Agronômico (IAC), Campinas - SP, rcmpires@iac.sp.gov.br

${ }^{4}$ Eng ${ }^{0}$ Agrônomo, Professor Titular, Universidade Federal Rural de Pernambuco, Garanhuns - PE.

${ }^{5}$ Eng ${ }^{0}$ Agrônomo, Casa de Agricultura de Itobi, Regional São João da Boa Vista, CATI, Itobi - SP.

Recebido pelo Conselho Editorial em: 14-6-2006
}

Aprovado pelo Conselho Editorial em: 3-4-2007 
hídrica no solo tem fundamental importância para o estabelecimento, desenvolvimento da cultura e produção de tubérculos (MAROUELLI, 1997), sendo a mesma sensível ao déficit e ao excesso de água no solo (OLIVEIRA \& VALADÃO, 1999).

SCALOPI et al. (1975), realizando trabalho com tensões de água no solo de 30;60;100;300 e $1.000 \mathrm{kPa}$, associadas a diferentes níveis de adubação, na cultura da batata, observaram que tensões acima de $100 \mathrm{kPa}$ afetam negativamente a produtividade de tubérculos. Os autores verificaram que existe relação positiva entre a área foliar e a produção de tubérculos.

Para verificar o efeito de três níveis de água disponível no solo, no desenvolvimento de plantas de batata, cultivar Baronesa, e na produção e na qualidade dos tubérculos, FRANKE et al. (1994) submeteram as plantas às tensões de água no solo de 45 e $85 \mathrm{kPa}$ e sem irrigação. Os autores observaram que a tensão de $45 \mathrm{kPa}$ proporcionou índice de área foliar superior aos demais tratamentos. No entanto, a produção de tubérculos foi menor na tensão de $45 \mathrm{kPa}$, comparada com a tensão de $85 \mathrm{kPa}$, e maior quando comparada com o tratamento sem irrigação. As tensões impostas não interferiram na qualidade dos tubérculos, com relação às classes de distribuição.

Visando a verificar o efeito de três regimes de umidade do solo no crescimento de plantas de batata, SCALOPI \& FERRAZ (1978) observaram que o maior déficit hídrico imposto (500 kPa) após o completo desenvolvimento vegetativo antecipou a senescência das plantas em relação aos tratamentos com menores tensões $(50$ e $100 \mathrm{kPa})$. Resultados semelhantes foram observados por AGUIAR NETTO et al. (2000), que também submeteram plantas de batata a diferentes tensões de água no solo $(15 ; 35 ; 55 ; 75$ e $1.500 \mathrm{kPa})$ e verificaram que a redução nas lâminas de irrigação, ou seja, maiores tensões de água no solo afetam negativamente o crescimento dos tubérculos da cultivar Aracy.

Assim como a deficiência hídrica, o excesso de água no solo também pode comprometer o desenvolvimento vegetativo das plantas de batata e, conseqüentemente, provocar perdas significativas na produção de tubérculos. MIRANDA FILHO et al. (1998) e FLECHA et al. (2004) relatam que a cultura da batata é bastante sensível ao encharcamento. Irrigações muito freqüentes, para manter a disponibilidade hídrica no solo, superiores a 90\%, apresentaram tendência de diminuição na produção de batata, conforme relatado por SCALOPI et al. (1975), evidenciando a importância do monitoramento da água no solo para obtenção de resultados positivos.

A irrigação na cultura da batata vem sendo realizada tradicionalmente por aspersão, seja convencional, autopropelido, seja pivô-central. No entanto, alguns aspectos fundamentais à sustentabilidade da atividade agrícola irrigada não estão sendo contemplados. O primeiro é relacionado à sanidade da cultura. $\mathrm{O}$ molhamento das folhas provocado pela aspersão favorece a maior incidência de doenças de folha (OLIVEIRA \& VALADÃO, 1999). O segundo é o uso múltiplo da água. Diante do cenário atual de competitividade pelo uso da água e problemas relacionados à disponibilidade dos recursos hídricos, há necessidade de alternativas para economia de tal insumo na irrigação. Para tanto, tem-se procurado investigar o desempenho, bem como estratégias de cultivo e manejo para adoção de sistemas de irrigação caracterizados por propiciarem redução no desperdício da água. Nesse aspecto, a irrigação por gotejamento tem sido avaliada e adotada com êxito para diversas culturas. ERDEM et al. (2006) obtiveram maior eficiência do uso da água no cultivo com a batata irrigada por gotejamento, comparada à irrigação por sulcos, na Turquia. GARCIA et al. (2003), em Botucatu, avaliaram o desempenho da cultura da batata em plantio com linhas simples e dupla, irrigada por gotejamento superficial e subsuperficial. Com os resultados, os autores constataram que o cultivo em linha dupla com irrigação subsuperficial proporcionou maior produtividade de tubérculos. No entanto, a população de plantas adotada foi diferente em ambos os espaçamentos de cultivo. Tal fato pode ter favorecido a produtividade no plantio em linhas duplas.

Portanto, em razão da necessidade de utilizar racionalmente os recursos hídricos e gerar informações relacionadas aos cultivos irrigados, teve-se o objetivo de avaliar dois sistemas de cultivo que refletem diretamente o dimensionamento do sistema de irrigação por gotejamento para a cultura da batata, utilizando como variáveis de comparação o crescimento e a produtividade. 


\section{MATERIAL E MÉTODOS}

O experimento foi conduzido no Sítio São Miguel, localizado no município de Itobi - SP, cujas coordenadas geográficas são $21^{\circ} 41^{\prime} 15^{\prime}$ 'S de latitude sul e 46 56'15" de longitude oeste. As características químicas e físicas do solo encontram-se nas Tabelas 1 e 2, respectivamente.

TABELA 1. Análise química do solo da área do experimento no município de Itobi - SP.

\begin{tabular}{cccccccccccc}
\hline Profundidade & \multicolumn{2}{c}{$\mathrm{pH}$} & $\mathrm{M} . \mathrm{O}$. & $\mathrm{P}$ & $\mathrm{K}$ & $\mathrm{Ca}$ & $\mathrm{Mg}$ & $\mathrm{Al}$ & $\mathrm{H}$ & $\mathrm{CTC}$ & $\mathrm{V}$ \\
\hline$(\mathrm{m})$ & $\mathrm{CaCl}_{2}$ & $\mathrm{H}_{2} \mathrm{O}$ & $\left(\mathrm{g} \mathrm{dm}^{-3}\right)$ & $\left(\mathrm{mg} \mathrm{dm}^{-3}\right)$ & $-------------\left(\mathrm{mmol}_{\mathrm{c}} \mathrm{dm}^{-3}\right)$ & ------------- & $(\%)$ \\
\hline $0-0,2$ & 5,4 & 6,2 & 10,0 & 14,2 & 2,23 & 33,0 & 9,0 & 1,0 & 30,0 & 75,2 & 58,8 \\
$0,2-0,4$ & 5,4 & 6,1 & 11,0 & 22,2 & 2,69 & 38,0 & 5,0 & 1,0 & 27,0 & 73,7 & 62,0 \\
$0,4-0,6$ & 5,5 & 6,3 & 12,0 & 12,4 & 2,66 & 33,0 & 7,0 & 1,0 & 27,0 & 70,7 & 60,4 \\
\hline
\end{tabular}

TABELA 2. Análise física do solo na área do experimento no município de Itobi - SP.

\begin{tabular}{|c|c|c|c|c|c|c|c|c|}
\hline \multirow{3}{*}{$\begin{array}{l}\text { Profundidade } \\
\text { (m) }\end{array}$} & \multicolumn{5}{|c|}{ Composição Granulométrica (\%) } & \multirow{2}{*}{\multicolumn{2}{|c|}{$\begin{array}{l}\text { Densidade } \\
\left(\mathrm{g} \mathrm{cm}^{-3}\right)\end{array}$}} & \multirow{3}{*}{$\begin{array}{l}\text { Porosidade } \\
\text { (\%) }\end{array}$} \\
\hline & \multicolumn{2}{|c|}{ Areia } & \multirow{2}{*}{ Limo } & \multirow{2}{*}{ Argila } & \multirow{2}{*}{ Cascalho } & & & \\
\hline & Grossa & Fina & & & & Solo & Partículas & \\
\hline $0-0,2$ & 48,0 & 13,0 & 9,0 & 30,0 & 0,0 & 1,17 & 2,47 & 52,6 \\
\hline $0,2-0,4$ & 54,0 & 10,0 & 4,0 & 32,0 & 0,0 & 1,37 & 2,50 & 45,2 \\
\hline $0,4-0,6$ & 51,0 & 13,0 & 5,0 & 31,0 & 0,0 & 1,17 & 2,47 & 52,6 \\
\hline
\end{tabular}

O clima da região é Cwa, segundo Köeppen, caracterizado como subtropical, quente com inverno seco (SETZER, 1966). Para a determinação da precipitação, foram instalados, ao lado da área de cultivo, um pluviômetro tipo "Ville de Paris" e um tanque Classe A (PEREIRA et al., 2002). Para a estimativa da evapotranspiração de referência (ETo), a partir da evaporação do tanque Classe A, foi estimado o tanque Classe A a partir de dados de velocidade do vento e umidade relativa medidas em estação meteorológica automática situada acerca de $3.000 \mathrm{~m}$ de distância da área experimental, conforme ALLEN et al. (1998).

O delineamento experimental utilizado foi o de blocos ao acaso, com dois tratamentos e oito repetições. Os tratamentos foram definidos de acordo com o sistema de plantio, por parcelas cultivadas em linhas simples (LS), considerando o espaçamento praticado tradicionalmente pelos agricultores, ou seja, de 0,75 m entre linhas, e por linhas duplas (LD), cujo espaçamento foi de 0,60 e $0,90 \mathrm{~m}$ alternadas entre elas. Para cada linha simples de cultivo, havia uma linha de tubogotejador, enquanto no cultivo em linhas duplas instalou-se um tubogotejador entre as linhas de cultivo do menor espaçamento $(0,60 \mathrm{~m})$, conforme Figura 1.

A

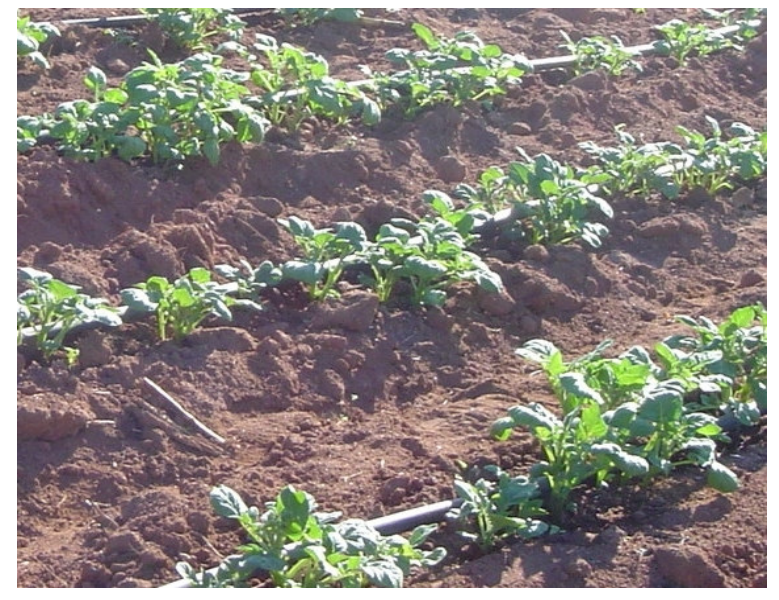

B

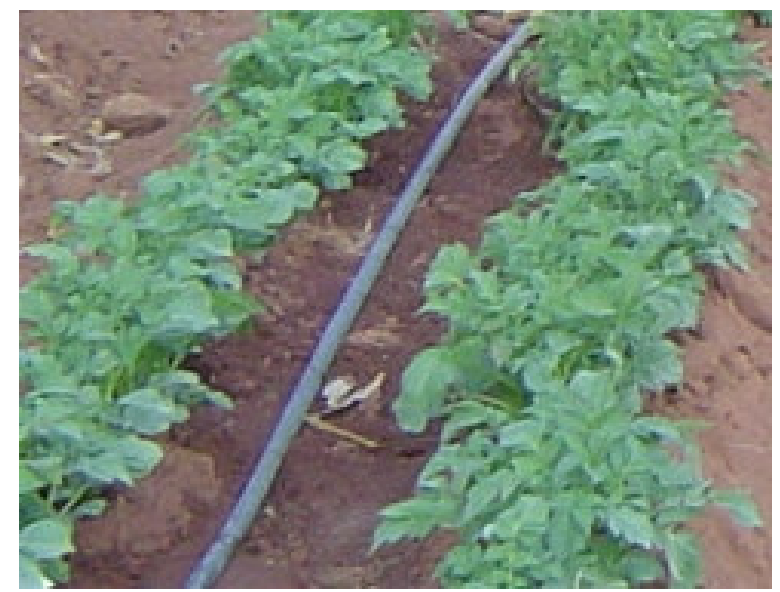

FIGURA 1. Sistemas de plantio da cultura da batata irrigados por gotejamento. Linha simples (A) e linhas duplas (B). 
Nas linhas de plantio, em ambos os tratamentos, o espaçamento entre as batatas-semente foi de 0,15 a $0,20 \mathrm{~m}$, conforme MIRANDA FILHO et al. (1998). A área do experimento foi de $60 \times 40 \mathrm{~m}$, totalizando $2.400 \mathrm{~m}^{2}$. As parcelas cultivadas com linhas simples foram constituídas de nove linhas de plantio de $15 \mathrm{~m}$ de comprimento, e as parcelas com linhas duplas, por oito linhas de plantio, ou seja, quatro linhas duplas de $15 \mathrm{~m}$ de comprimento. A área total de cada parcela foi, respectivamente, 101,2 e $90 \mathrm{~m}^{2}$.

O preparo do solo constou de uma aração e duas gradagens. Em ambos os sistemas de cultivo, a adubação de plantio foi de 3,3 $\mathrm{t} \mathrm{ha}^{-1}$ da fórmula 02-19-06, enquanto a de cobertura foi de 0,62 $\mathrm{t} \mathrm{ha}^{-1}$ da fórmula 20-00-20. A adubação de cobertura foi aplicada via fertirrigação aos 30; $42 \mathrm{e}$ 50 dias após o plantio (DAP).

A cultivar utilizada foi a Monalisa, cujas características agronômicas são ciclo precoce, semierecta, hastes pouco vigorosas, folhas grandes, tubérculos de formato oval-alongado, com película amarela lisa, brilhante, resistente ao esverdeamento, medianamente sensível ao embonecamento e rachaduras e ciclo vegetativo variando entre 90 e 110 dias (SANTOS et al., 1986; MELO \& BUSO, 1997), sendo uma das principais cultivares plantadas no Brasil (MELO, 1999). O plantio foi realizado no dia 19 de abril de 2005.

A linha de irrigação no cultivo em linha simples possuía emissores com vazão de $1,6 \mathrm{~L} \mathrm{~h}^{-1}$ espaçados em $0,60 \mathrm{~m}$, e no cultivo em linha dupla, a vazão dos emissores foi a mesma, porém espaçados em 0,40 m. A uniformidade de distribuição foi determinada de acordo com BRALTS \& KESNER (1983) e FRIZZONE \& DOURADO NETO (2003), com valores de 95 e 93\% para linha simples e linha dupla, respectivamente.

Para o monitoramento do potencial matricial de água no solo, foram instaladas duas estações de controle por tratamento, com tensiômetros nas profundidades de 0,20;0,40 e 0,60 m.

Durante o ciclo da cultura, as irrigações foram realizadas duas a três vezes por semana, utilizando como critério a manutenção da tensão de água no solo entre 15 e $50 \mathrm{kPa}$ (SCALOPI et al., 1975; MAROUELLI et al., 1988; AGUIAR NETTO et al., 2000), na profundidade de 0,20 m. Os tensiômetros instalados a 0,40 e $0,60 \mathrm{~m}$ de profundidade serviram para monitorar o volume de bulbo molhado, auxiliando nos ajustes necessários de lâminas de irrigação durante o ciclo da cultura (PIRES et al., 2001).

Foram realizadas avaliações de índice de área foliar (IAF), massa seca da parte aérea (MSPA) e produção de tubérculos. Para a obtenção do IAF e da MSPA, foram coletadas ao longo do ciclo da cultura aos 28; 42 e 64 DAP, duas plantas com três repetições por tratamento. As duas primeiras amostragens foram realizadas quando as plantas estavam no estádio vegetativo, e a última, durante o estádio de tuberização (SAKAI et al., 2003). As plantas foram cortadas rentes ao solo, acondicionadas em sacos de plásticos e encaminhadas para laboratório, onde foram lavadas e separadas as folhas das demais partes para a determinação da área foliar. A área foliar foi determinada utilizando-se de integrador de área foliar (LICOR LI-3100). O IAF foi obtido pela razão entre a área foliar da planta e a área por ela ocupada (MAGALHÃES, 1985). Para a determinação da MSPA, todo material foi acondicionado em sacos de papel e colocado em estufa a $60{ }^{\circ} \mathrm{C}$ para secagem, até massa constante.

Aos 118 DAP (15-8-2005), para a obtenção da produção total de tubérculos, foram colhidas, em cada parcela, duas linhas de dois metros de comprimento, no tratamento em linha simples, e uma linha dupla de dois metros de comprimento, no tratamento em linha dupla. Em ambos os tratamentos, a área útil colhida por parcela para estimativa da produção foi de $3 \mathrm{~m}^{2}$. Cada amostra foi lavada e sua massa determinada em balança com capacidade mínima de 0,2 $\mathrm{kg}$ e máxima de $50 \mathrm{~kg}$. A partir da massa de cada amostra, realizou-se a estimativa da produtividade. Posteriormente, os tubérculos foram classificados de acordo com o diâmetro transversal, sendo classe 1, valores acima de $85 \mathrm{~mm}$; classe 2, maiores ou iguais a $45 \mathrm{~mm}$ e menores que $85 \mathrm{~mm}$; classe 3, maiores ou iguais a $33 \mathrm{~mm}$ e menores que $45 \mathrm{~mm}$, e classe 4 , os menores que $33 \mathrm{~mm}$ (LUENGO et al., 1999). 
Os resultados de massa seca da parte aérea, índice de área foliar e produção total de tubérculos foram submetidos à análise de variância. Os resultados de MSPA e IAF obtidos foram avaliados nos diferentes tratamentos para cada época de amostragem, separadamente. As médias foram comparadas pelo teste de Tukey, a 5\% de probabilidade.

\section{RESULTADOS E DISCUSSÃO}

A cultura da batata é exigente em água, sendo sensível à deficiência e ao excesso da mesma. O consumo de água na cultura varia em torno de 280 a $700 \mathrm{~mm}$, dependendo das condições de clima, solo e planta (PEREIRA et al., 1995; MAROUELLI, 1997; OLIVEIRA \& VALADÃO, 1999; ERDEM et al., 2006). Os valores de precipitação e evapotranspiração de referência (ETo) ocorridos durante o período experimental encontram-se na Figura 2.

Durante o experimento, a precipitação total foi de $163 \mathrm{~mm}$, ocorrida em apenas nove dias, e $70 \%$ das chuvas se concentraram num período de cinco dias (23 a 27 de maio de 2005). O maior intervalo entre as precipitações chegou a atingir 24 dias. A evapotranspiração de referência média no período avaliado foi cerca de $2 \mathrm{~mm}$. Para complementar a necessidade hídrica da cultura, durante a condução do experimento, foram realizadas irrigações que totalizaram lâmina líquida média de $242 \mathrm{~mm}$. Valores de lâmina de irrigação semelhantes no cultivo da batata também foram verificados em condições de irrigação complementar às chuvas no município de São Manuel - SP (AGUIAR NETTO, 2000). RODRIGUEZ ROBLES (2003) aplicou lâmina de irrigação menor que a do presente estudo no cultivo da batata, em Piracicaba - SP. Entretanto, a lâmina de água adicionada ao solo (chuva mais irrigação) foi semelhante à do presente trabalho.

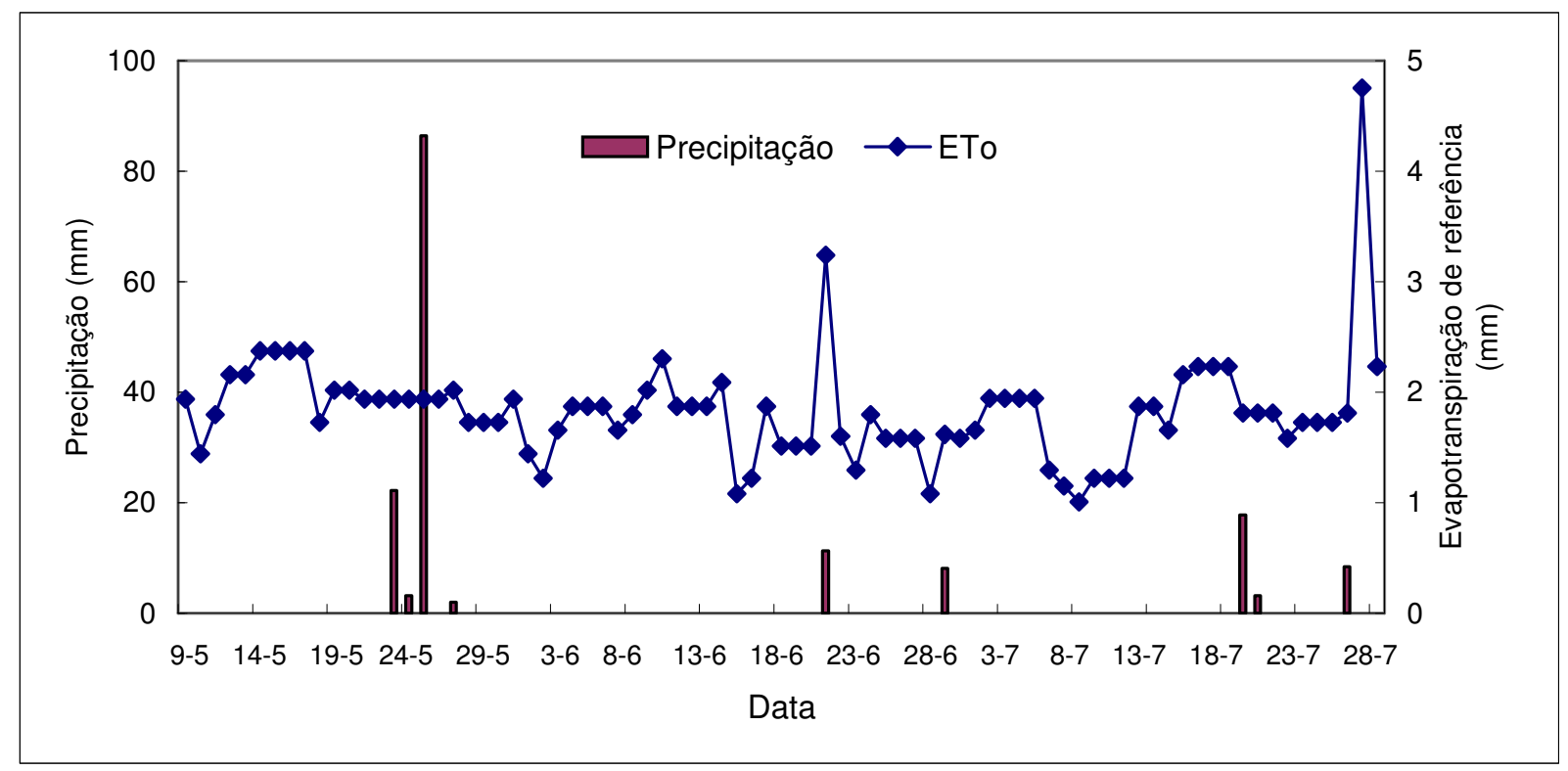

FIGURA 2. Valores diários de precipitação e evapotranspiração de referência (ETo) estimada pelo tanque Classe A ocorridos durante a experimentação, em Itobi -SP.

O IAF e a MSPA obtidos durante o ciclo da cultura, nos dois sistemas de plantio irrigados por gotejamento, encontram-se na Tabela 3. Constata-se que, nas três épocas avaliadas, o IAF e a MSPA das plantas, em ambos os tratamentos, não diferiram estatisticamente entre si. Em relação ao IAF, verificou-se que, em ambos os sistemas de cultivo, o maior valor ocorreu aos 42 DAP; no entanto, no cultivo em linha LD, a redução da área foliar na última amostragem foi menor do que no cultivo em LS.

O comportamento do IAF obtido nos dois sistemas de cultivo foi semelhante aos apresentados por AGUIAR NETTO et al. (2000), que obtiveram pico com valor próximo a 3,5 aplicando lâmina de irrigação semelhante à do presente estudo. Vale salientar que a cultivar e a população de plantas utilizadas pelos autores foram diferentes das utilizadas neste experimento. RODRIGUEZ ROBLES (2003) observou valores superiores de IAF ao longo do ciclo comparados 
ao presente trabalho (Tabela 3). As menores diferenças entre tratamentos foram observadas aos 42 DAP (Tabela 3).

TABELA 3. Valores médios de índice de área foliar (IAF) e massa seca da parte aérea (MSPA) obtidos durante o ciclo de desenvolvimento da cultura da batata cultivada em linhas simples (LS) e linhas duplas (LD), aos 28; 42 e 64 dias após o plantio, em Itobi - SP*.

\begin{tabular}{|c|c|c|c|}
\hline \multirow{2}{*}{ Tratamentos } & \multicolumn{3}{|c|}{ Dias Após o Plantio } \\
\hline & 28 & 42 & 64 \\
\hline & \multicolumn{3}{|c|}{$\operatorname{IAF}\left(\mathrm{m}^{2} \mathrm{~m}^{-2}\right)$} \\
\hline LS & $1,33 \mathrm{a}$ & $3,11 \mathrm{a}$ & $1,77 \mathrm{a}$ \\
\hline LD & $1,53 \mathrm{a}$ & $3,11 \mathrm{a}$ & $2,85 \mathrm{a}$ \\
\hline C.V. $(\%)$ & 30,40 & 14,50 & 25,60 \\
\hline \multirow[t]{2}{*}{$\underline{\mathrm{DMS}^{* *}}$} & 0,98 & 1,02 & 1,33 \\
\hline & \multicolumn{3}{|c|}{ MSPA (g planta ${ }^{-1}$ ) } \\
\hline LS & $11,6 \mathrm{a}$ & $19,7 \mathrm{a}$ & $11,7 \mathrm{a}$ \\
\hline LD & $10,2 \mathrm{a}$ & $19,9 \mathrm{a}$ & $18,1 \mathrm{a}$ \\
\hline C.V. $(\%)$ & 31,3 & 17,1 & 27,5 \\
\hline DMS** & 7,7 & 7,6 & 9,2 \\
\hline
\end{tabular}

* Médias seguidas pela mesma letra na coluna, para cada variável analisada, não diferem entre si, a 5\% de probabilidade, pelo teste de Tukey. ** DMS: diferença mínima significativa, a 5\% de probabilidade, pelo teste de Tukey.

Corroborando os valores de IAF obtidos, a MSPA apresentou comportamento semelhante. Verificou-se que até a segunda amostragem (42 DAP), tanto o plantio em linha simples, quanto o plantio em linha dupla apresentaram crescente acúmulo de MSPA (Tabela 3). Devido às plantas no cultivo em linha dupla terem visualmente tido maior desenvolvimento vegetativo, como foi registrado pelos valores de IAF obtidos aos 64 DAP, essas apresentaram também valores mais elevados de MSPA que os observados no plantio em linha simples, porém sem diferirem estatisticamente. RODRIGUES ROBLES (2003) observou valores de MSPA por planta superiores aos apresentados na Tabela 3 ao longo do ciclo. No entanto, a população de plantas era menor que $50 \%$ do utilizado no presente trabalho. COGO et al. (2006) observaram valores menores de MSPA da cultura da batata que os apresentados na Tabela 3 em cultivo em substrato, em telado.

A produtividade total de tubérculos, conforme Tabela 4, foi significativamente maior em cerca de $18 \%$ no cultivo em linha dupla, comparado ao plantio em linhas simples, de 26,5 e $22,5 \mathrm{t} \mathrm{ha}^{-1}$, respectivamente. A produção obtida na linha simples está próxima à da média obtida em São Paulo (23,3 t ha $\left.{ }^{-1}\right)$. De acordo com as Tabelas 1 e 2, não houve impedimento químico e físico do solo ao bom desenvolvimento e à produção da cultura. Os resultados da Tabela 4 são semelhantes aos obtidos por GARCIA et al. (2003), que avaliaram a produtividade de tubérculos de batata, sob dois sistemas de plantio, irrigados por gotejamento, e obtiveram maiores produtividades no cultivo em linha dupla, comparado com o cultivo em linha simples. No entanto, a população de plantas entre os tratamentos favoreceu o cultivo em linha dupla. Tal fato difere do presente estudo, que avaliou os dois tratamentos para a mesma população de plantas. FELTRAN (2002) estudou o desempenho produtivo de 18 cultivares de batata plantadas com irrigação complementar na estação das águas. A produtividade comercial variou de 9,5 a 39,5 t ha ${ }^{-1}$, sendo em média 18,6 t ha ${ }^{-1}$; no entanto, não estudou a cultivar Monalisa. RODRIGUES ROBLES (2003), apesar de valores de IAF e MSPA superiores aos do presente estudo (Tabela 3), alcançaram valores de produtividade abaixo dos observados na Tabela 4.

Embora os valores de IAF não tenham diferido significativamente entre os tratamentos (Tabela 3), esse índice foi cerca de $60 \%$ maior na linha dupla, na terceira avaliação. Verifica-se no presente estudo que, quando a área foliar foi maior, houve resposta positiva na produção, sugerindo que há relação positiva entre área foliar e produção de tubérculos, concordando com os resultados de SCALOPI et al. (1975) e discordando dos de FRANKE et al. (1994). 
Considerando-se a classificação dos tubérculos de batata, de acordo com o diâmetro transversal, conforme LUENGO et al. (1999), observou-se que, no cultivo em linhas simples, 35\% e $65 \%$ da produção pertenciam às classes 2 e 3, respectivamente, e no cultivo em linhas duplas, $33 \%$ e $67 \%$, respectivamente. As diferenças percentuais relativas à classificação da produção nos dois sistemas de cultivo não ultrapassaram 2\%. RODRIGUEZ ROBLES (2003), apesar de produtividade abaixo das alcançadas no presente trabalho, obteve a maior parte da produção como classe 1 .

TABELA 4. Produtividade de tubérculos obtidos em função do sistema de plantio em linhas duplas (LD) e linhas simples (LS), irrigado por gotejamento, em Itobi - SP. *

\begin{tabular}{lc}
\hline Tratamentos & Produtividade $\left(\mathrm{t} \mathrm{ha}^{-1}\right)$ \\
\hline LD & $26,5 \mathrm{a}$ \\
LS & $22,5 \mathrm{~b}$ \\
\hline C.V. $(\%)$ & 13,8 \\
DMS** & 3,9 \\
\hline
\end{tabular}

* Médias seguidas de mesma letra não diferem entre si, a 5\% de probabilidade, pelo teste de Tukey.

** DMS: diferença mínima significativa, a 5\% de probabilidade, pelo teste de Tukey.

A adoção do sistema de cultivo em linhas simples ou duplas no cultivo da batata irrigada por gotejamento tem influência direta no custo do sistema de irrigação, uma vez que o cultivo em linhas simples com uma linha de tubogotejador por linha de plantio utiliza o dobro da quantidade necessária quando adotado o plantio em linhas duplas com uma linha de tubogotejador a cada duas linhas de plantio. Dessa forma, essa informação tem importância fundamental para projetistas, consultores e agricultores, uma vez que interfere nos custos do sistema de irrigação, bem como nos custos referentes à instalação e retirada do equipamento no campo, uma vez que a cultura da batata não deve ser cultivada na mesma área no ciclo seguinte. Por outro lado, a adoção de linhas duplas com uma linha de tubogotejadores entre o espaçamento menor propiciou aumento na produção em $18 \%$.

\section{CONCLUSÕES}

O sistema de plantio em linha dupla proporcionou maior produtividade de tubérculos, tornando-se uma alternativa para o cultivo da batata cv. Monalisa, irrigada por gotejamento, necessitando apenas de $50 \%$ da quantidade de tubogotejadores em relação ao sistema de cultivo em linhas simples.

\section{REFERÊNCIAS}

AGUIAR NETTO, A.O.; RODRIGUES, J. D.; PINHO, S. Z. Análise de crescimento da cultura da batata submetida a diferentes lâminas de irrigação. Pesquisa Agropecuária Brasileira, Brasília, v.35, n.5, p.901-7, 2000.

ALLEN, R.G.; PEREIRA, L.S.; RAES, D.; SMITH, M. Crop evapotranspiration - gidelines for computing crop water requirements. Roma: FAO, 1998. 300 p. (Irrigation and Drainage, Paper 56).

BRALTS, V.F.; KESNER, C.D. Drip irrigation field uniformity estimation. Transactions of the ASAE, St. Joseph, v.24, n.5, p.1369-74, 1983.

COGO, C.M.; ANDRIOLO, J.L.; BISOGNIN, D.A.; GODOI, R.S.; BORTOLOTTO, O.C.; BARROS, G.T. Crescimento, produtividade e coloração dos chips de tubérculos de batata produzidos sob alta disponibilidade de potássio. Ciência Rural, Santa Maria, v.36, n.3, 2006. Disponível em:

$<$ http://www.scielo.br/scielo.php?script=sci_arttext\&pid=S0103847820060003000 42\&lng=em\&nr m=isso $>$. Acesso em: 15 jan 2007. 
ERDEM, T.; ERDEM, Y.; ORTA, H.; OKURSOY, H. Water-yield relationships of potato under different irrigation methods and regimens. Scientia Agricola, Piracicaba, v.63, n.3, p.226-31, 2006.

FELTRAN, J. C. Determinação das características agronômicas, dos distúrbios fisiológicos, do estado nutricional da planta e da qualidade dos tubérculos em cultivares de batata (Solanum tuberosum L.). 2002. 106 f. Dissertação (Mestrado em Agricultura) - Faculdade de Ciências Agronômicas, Universidade Estadual Paulista, Botucatu, 2002.

FLECHA, P.A.N.; MINGOTI, R.; DUARTE, S.N.; MIRANDA, J.H.; CRUCIANI, D.E. Sensibilidade da cultura da batata ao excesso de água no solo. Anais... In: CONGRESSO BRASILEIRO DE ENGENHARIA AGRÍCOLA, 33., 2004, São Pedro. Anais... Jaboticabal: SBEA, 2004. 1 CD-ROM.

FRANKE, A.E.; MARTINI, L.C.P.; KONING, O.; POZZEBON, E.; LIBERALESSO, R.A. Efeito da irrigação no rendimento e na qualidade dos tubérculos na cultura da batata (Solanum tuberosum L.). Revista Ceres, Viçosa, v.41, n.236, p.367-78, 1994.

FRIZZONE, J.A.; DOURADO NETO, D. Avaliação de sistemas de irrigação. In: MIRANDA, J.H.; PIRES, R.C.M. Irrigação. Jaboticabal: SBEA, 2003. v.2, p.573-651. (Série Engenharia Agrícola)

GARCIA, C.J.B.; DALRI, A.B.; ANDRADE, A.R.; OLIVEIRA, M.V.A.M.; CRUZ, R.L. Irrigação por gotejamento superficial e subsuperficial na cultura da batata com dois sistemas de plantio. Revista Irriga, Botucatu, v.8, n.2, p.150-9, 2003.

LUENGO, R.F.A.; CALBO, A.G.; ANA, M.M.; MORETTI, C.L.; HENZ, G.P. Classificação de hortaliças. Brasília: Embrapa Hortaliças, 1999. 61 p. (Documentos, 22).

MAGALHÃES, A.C.N. Análise quantitativa de crescimento. In: FERRI, M.G. Fisiologia vegetal 1. 2.ed. (revisada). São Paulo:E.P.U/EDUSP, 1985. p.333-50.

MAROUELLI, W.A. Irrigação. In: LOPES, C.A.; BUSO, J.A. Cultivo da batata (Solanum tuberosum L.). Brasília: Embrapa Hortaliças, 1997. p.16-19. (Instruções Técnicas, 8).

MAROUELLI, W.A.; SILVA, H.R.; OLIVEIRA, C.A.S.; SILVA, H.R. Resposta da batata a diferentes regimes de irrigação. Revista Latinoamericana da la Papa, Lima, v.1, n.1, p.25-34, 1988.

MELO, P.E. Cultivares de batata potencialmente úteis para processamento na forma de fritura no Brasil e manejo para obtenção de tubérculos adequados. Informe Agropecuário, Belo Horizonte, v.20, n.197, p.112-19, 1999.

MELO, P.E.; BUSO, J.A. Principais cultivares. In: LOPES, C.A.; BUSO, J.A. Cultivo da batata (Solanum tuberosum L.). Brasília: Embrapa Hortaliças, 1997. p.4-8. (Instruções Técnicas, 8).

MIRANDA FILHO, H.S.; GRANJA, N.P.; DIAS, J.A.C.S.; RAMOS, V.J. Batata. In: FAHL, J.I.; CAMARGO, M.B.P.; PIZZIONATO, M.A.; BETTI, J.A.; MELO, A.M.T.; MARIA I.C.;

FURLANI, M.A.C. (Org.). Instruções agrícolas para as principais culturas econômicas. 6.ed. (revisada). Campinas: Instituto Agronômico,1998. 396 p. (Boletim 200)

NEHMI, I.M.D.; FERRAZ, J.V.; NEHMI FILHO, V.A.; SILVA, M.L.M. (Coord.). Anuário da agricultura brasileira. São Paulo: FNP Consultoria e Agroinformativos, 2004. 496 p.

OLIVEIRA, C.A.S.; VALADÃO, L.T. Manejo da irrigação na cultura da batata. Informe Agropecuário, Belo Horizonte, v.20, n.197, p.72-6, 1999.

PEREIRA, A.R.; ANGELOCCI, L.R.; SENTELHAS, P.C. Agrometeorologia: fundamentos e aplicações práticas. Guaíba: Agropecuária, 2002. 478 p.

PEREIRA, A.; PEDRAS, J.F.; VILLA NOVA, N.A.; CURY, D.M. Consumo d'água e coeficiente de cultura da batata (Solanum tuberosum L. cv. Itararé) em plantio de inverno no município de Botucatu - SP. Revista Brasileira de Agrometeorologia, Santa Maria, v.3, n.1, p.59-62, 1995. 
PIRES, R.C.M.; SAKAI, E.; ARRUDA, F.B.; FOLEGATTI, M.V. Necessidades hídricas das culturas e manejo da irrigação. In: MIRANDA, J.H.; PIRES, R.C.M. Irrigação. Jaboticabal: SBEA, 2001. v.1, p.121-94. (Série Engenharia Agrícola).

RODRIGUEZ ROBLES, W.G. Dióxido de carbono via fertirrigação em batateira (Solanum tuberosum L.) sob condições de campo. 2003. 160 f. Tese (Doutorado em Irrigação e Drenagem) Escola Superior de Agricultura “Luiz de Queiroz”, Universidade de São Paulo, Piracicaba, 2003.

SAKAI, E.; ARRUDA, F.B.; PIRES, R.C.M. Manejo da irrigação em tomate e batata. In: REUNIÃO ITINERANTE DE FITOSSANIDADE DO INSTITUTO BIOLÓGICO - TOMATE E BATATA, 8., 2003, Monte Alegre do Sul. Anais... Monte Alegre do Sul: Instituto Biológico, 2003. p.108-27.

SANTOS, M.M.E.D.; ANDRIGUETO, J.R.; CAMARGO, C.P. Descrição de cultivares de batata . Brasília: Secretaria Nacional de Produção Agropecuária, 1986. 40 p.

SCALOPI, E.J.; FERRAZ, E.C. Dependência do crescimento das plantas ao regime de umidade do solo. Anais da Escola Superior de Agricultura “Luiz de Queiroz”, Piracicaba, v.35, p.169-84, 1978.

SCALOPI, E.J.; SCARDUA, R.; KLAR, A.E. A influência da irrigação e adubação no rendimento, tamanho e número de tubérculos de batata (Solanum tuberosum L.). Anais da Escola Superior de Agricultura "Luiz de Queiroz", Piracicaba, v.32, p.385-94, 1975.

SETZER, J. Atlas climatológico e ecológico do Estado de São Paulo. Comissão Interestadual da Bacia Paraná-Uruguai, 1966. 61 p. 